\title{
An Innovative Australian Outreach Model of Diabetic Retinopathy Screening in Remote Communities
}

\author{
Nicola M. Glasson, ${ }^{1}$ Lisa J. Crossland, ${ }^{2}$ and Sarah L. Larkins ${ }^{1}$ \\ ${ }^{1}$ College of Medicine and Dentistry, James Cook University, 1 James Cook Drive, Townsville City, QLD 4811, Australia \\ ${ }^{2}$ Discipline of General Practice, University of Queensland, Level 8 Health Sciences Building, Royal Brisbane Hospital, \\ Herston, QLD 4029, Australia
}

Correspondence should be addressed to Nicola M. Glasson; nicola.glasson@my.jcu.edu.au

Received 13 June 2015; Revised 21 August 2015; Accepted 6 September 2015

Academic Editor: Ahmed Ibrahim

Copyright (C) 2016 Nicola M. Glasson et al. This is an open access article distributed under the Creative Commons Attribution License, which permits unrestricted use, distribution, and reproduction in any medium, provided the original work is properly cited.

\begin{abstract}
Background. Up to $98 \%$ of visual loss secondary to diabetic retinopathy (DR) can be prevented with early detection and treatment. Despite this, less than $50 \%$ of Australian and American diabetics receive appropriate screening. Diabetic patients living in rural and remote communities are further disadvantaged by limited access to ophthalmology services. Research Design and Methods. DR screening using a nonmydriatic fundal camera was performed as part of a multidisciplinary diabetes service already visiting remote communities. Images were onforwarded to a distant general practitioner who identified and graded retinopathy, with screenpositive patients referred to ophthalmology. This retrospective, descriptive study aims to compare the proportion of remote diabetic patients receiving appropriate DR screening prior to and following implementation of the service. Results. Of the 141 patients in 11 communities who underwent DR screening, $16.3 \%$ had received appropriate DR screening prior to the implementation of the service. In addition, $36.2 \%$ of patients had never been screened. Following the introduction of the service, $66.3 \%$ of patients underwent appropriate DR screening $(p=0.00025)$. Conclusion. This innovative model has greatly improved accessibility to DR screening in remote communities, thereby reducing preventable blindness. It provides a holistic, locally appropriate diabetes service and utilises existing infrastructure and health workforce more efficiently.
\end{abstract}

\section{Introduction}

In 2013, there were 382 million people with diabetes worldwide and it is predicted that this will increase to 592 million people by 2035 [1]. Diabetic retinopathy (DR) is the most serious ocular complication of diabetes and is the leading cause of preventable blindness in working age populations [2]. DR accounted for $5 \%$ of global blindness in 2002, approximately five million people worldwide [3]. It is estimated that up to $50 \%$ of people with proliferative DR who do not receive timely treatment will become legally blind within five years [4]. Although up to $98 \%$ of visual loss secondary to DR can be prevented with early detection and treatment, once it has progressed, vision loss is often permanent [5]. Despite this, comprehensive DR screening rates are poorly achieved globally, with less than $50 \%$ of Australian and American diabetic patients receiving appropriate screening $[6,7]$. The number of people with diabetes living in rural areas is increasing worldwide and is expected to reach 145 million people by 2035 [1]. Patients living in rural and remote areas have poorer access to specialist ophthalmology services $[8,9]$. Indigenous people worldwide are particularly vulnerable to eye disease, with blindness six times higher in Indigenous Australians than for non-Indigenous Australians $[1,10]$. Impaired vision affects national economies through loss of productivity and earning capacity as well as having significant negative social impacts on communities worldwide, with vision impaired individuals relying heavily on social support [1].

A review of international rural remote DR screening models by the authors found that the vast majority of published models use ophthalmologists as the primary image graders. Given the growing number of diabetic patients worldwide, poor achievement of screening recommendations, and limited access to ophthalmology services in rural 
TABLE 1: The documented diabetic population in remote communities visited by the screening program.

\begin{tabular}{|c|c|c|c|c|c|c|}
\hline \multirow[b]{2}{*}{ Remote community } & \multicolumn{2}{|l|}{2012} & \multicolumn{2}{|l|}{2013} & \multicolumn{2}{|c|}{2014} \\
\hline & $\begin{array}{c}\text { Documented } \\
\text { diabetic population } \\
(n)\end{array}$ & $\begin{array}{l}\text { Patients } \\
\text { screened } \\
\quad(n)\end{array}$ & $\begin{array}{c}\text { Documented } \\
\text { diabetic population } \\
(n)\end{array}$ & $\begin{array}{l}\text { Patients } \\
\text { screened } \\
\quad(n)\end{array}$ & $\begin{array}{c}\text { Documented } \\
\text { diabetic population } \\
(n)\end{array}$ & $\begin{array}{c}\text { Patients } \\
\text { screened } \\
(n)\end{array}$ \\
\hline 1 & 37 & 11 & 46 & 12 & \multicolumn{2}{|c|}{ No screening ${ }^{*}$} \\
\hline 2 & $10_{(2013)}$ & 4 & \multicolumn{2}{|c|}{ No screening } & \multicolumn{2}{|c|}{ No screening ${ }^{*}$} \\
\hline 3 & $3_{(2013)}$ & 3 & 3 & 4 & \multicolumn{2}{|c|}{ No screening ${ }^{*}$} \\
\hline 4 & 8 & 5 & $8_{(2012)}$ & 7 & $8_{(2012)}$ & 4 \\
\hline 5 & 10 & 2 & $10_{(2012)}$ & 1 & 10 & 6 \\
\hline 6 & 15 & 5 & 16 & 8 & 14 & 7 \\
\hline 7 & 39 & 13 & 49 & 18 & 35 & 17 \\
\hline 8 & 32 & 9 & 22 & 17 & 27 & 10 \\
\hline 9 & $7_{(2013)}$ & 1 & 7 & 1 & 13 & 8 \\
\hline 10 & 26 & 10 & 26 & 10 & 18 & 9 \\
\hline 11 & 15 & 5 & 14 & 5 & 15 & 6 \\
\hline Total & 202 & 68 & 201 & 83 & 140 & 67 \\
\hline $\begin{array}{l}\text { Diabetic population } \\
\text { screened (\%) }\end{array}$ & & $33.7 \%$ & & $41.3 \%$ & & $47.9 \%$ \\
\hline
\end{tabular}

Note: where no data was available on the diabetic population in a particular community from a specific year, the diabetic population is used from a previous year and indicated with the year in subscript.

Note: the diabetic population was documented from community health records. Lists were obtained from a chronic disease database and updated by PHCs and the regional diabetes educator. Patients were excluded if they were deceased or had moved from the district.

${ }^{*}$ These communities were screened early in 2015 due to changeover of the eye screening coordinator.

and remote communities, there is a recognised need for innovative approaches to the delivery of DR screening. This has led to trials utilising nonophthalmologist graders, with numerous studies demonstrating the efficacy of nonophthalmologist graders in detecting DR [4, 11-15]. This paper presents the results of the evaluation of an innovative remote outreach DR screening (RODRS) service delivered in remote communities in a state of Australia. The service aims to improve rates of DR screening for patients in remote settings with previously limited access to screening.

\section{The Remote Outreach DR Screening (RODRS) Service}

2.1. Existing Service. In 2012, the RODRS service was implemented in a Hospital District and Health Service in a state of Australia. Prior to 2012, visiting ophthalmologists and optometrists performed the majority of DR screening in the district. The implementation of the service was prompted by concerns that diabetic patients living in the region were not undergoing DR screening, and to utilise visiting ophthalmology services more efficiently. Optometrists and ophthalmologists service four rural and three remote communities in the region, with ophthalmologists visiting the district triannually (Figure 1). The RODRS program visits 11 remote communities in the district annually. These remote communities have nurse-led clinic facilities with visiting general practice services and three communities have visiting optometry and ophthalmology services. The documented diabetic population in each community ranges from 3 to 49 people and is listed in Table 1.

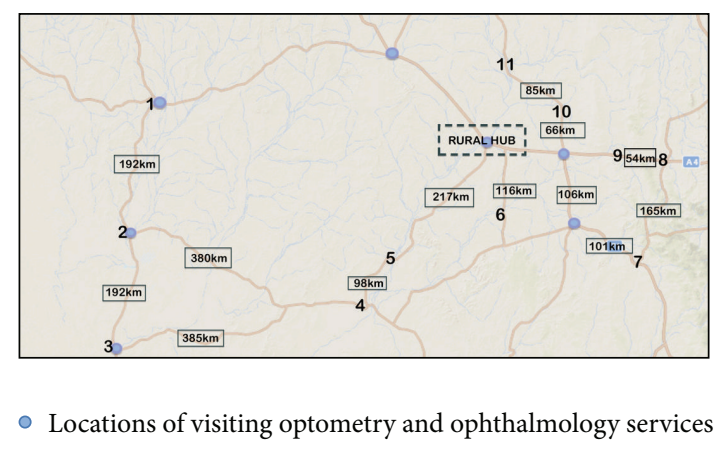

FIGURE 1: Remote communities visited by the RODRS program (listed 1 to 11).

2.2. Service Promotion and Patient Identification. Figure 2 presents a graphical representation of the outreach screening process. Diabetic patients are identified from a State Health chronic disease database. Patient lists are then sent to each primary health care centre (PHC) and the regional diabetes educator, who adjusts lists adding patients and removing those no longer living in the district. Diabetic patients are contacted by community health from the rural hub or by their local PHC to invite them for annual screening. Posters are displayed in community public areas and local health workers raise awareness of the screening visit. On the day of screening, local health workers visit residents in their homes to remind them of the visiting service and provide transport to clinics if required. 


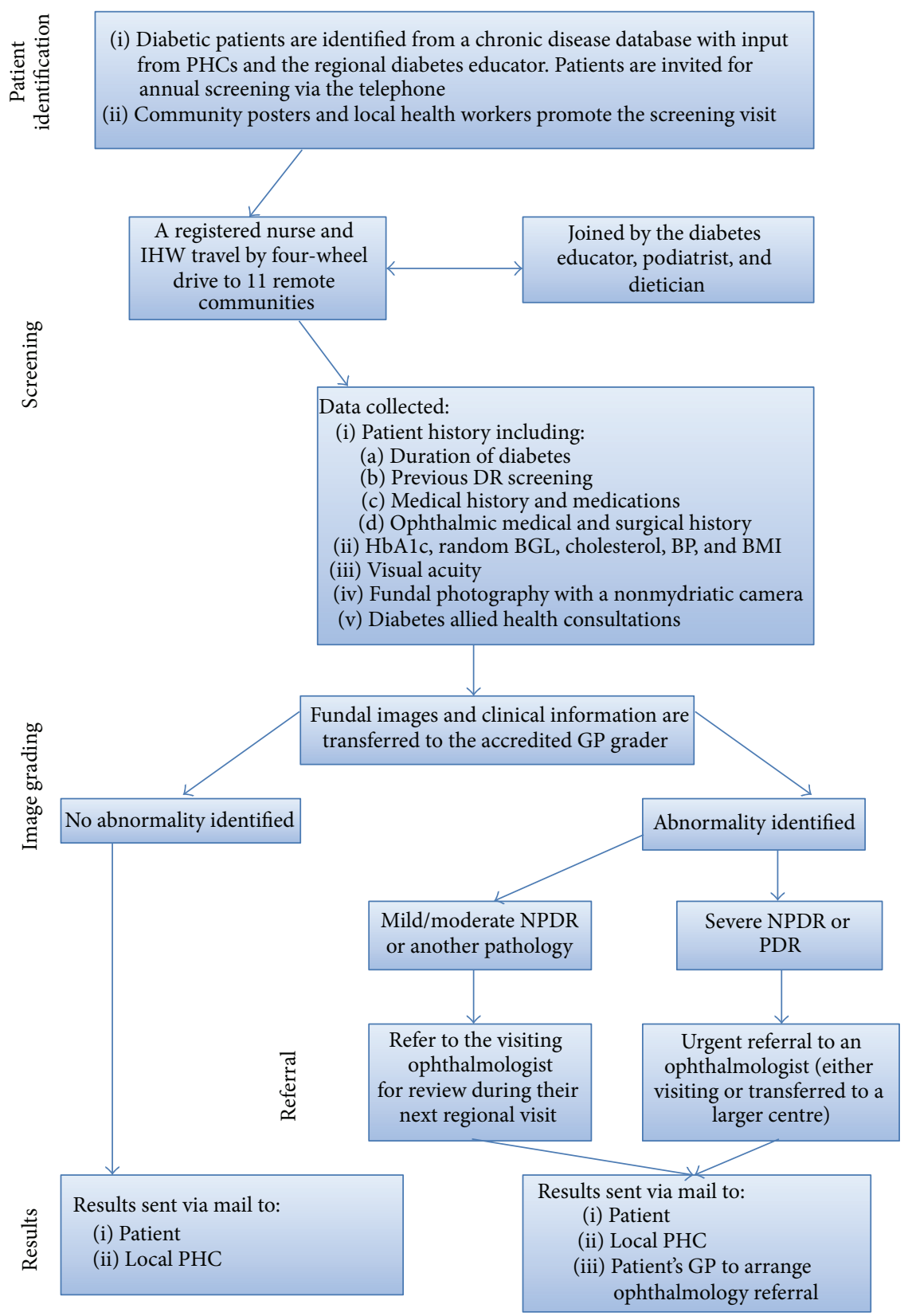

FIGURE 2: The remote outreach DR screening pathway.

2.3. Screening Visit. A registered nurse and Indigenous health worker (Indigenous refers to Aboriginal peoples and/or Torres Strait Islanders) (IHW) based in the rural hub travel via four-wheel drive to 11 remote communities with a fundal camera. This forms part of an existing chronic disease network in the district. Remote communities are located between $117 \mathrm{~km}$ and $693 \mathrm{~km}$ (approximately 1.5 to 7 hours' drive) from the rural hub, which itself is located $687 \mathrm{~km}$ from the closest major regional hospital and $1176 \mathrm{~km}$ from the state capital [16]. DR screening is performed in PHCs (except for one community where it is hospital-based). A brief patient history, random blood glucose level (BGL),
HbAlc, cholesterol level, blood pressure (BP), and body mass index (BMI) are collected. A visual acuity using a Snellen chart is then performed, with pinhole if required. Patients then undergo fundal photography by a registered nurse using an automated nonmydriatic camera (centervue DRS). One $45^{\circ}$ fundal photograph centred on the macula and with view of the optic nerve is captured of each eye. If an adequate image cannot be acquired, patients undergo dilation with tropicamide (Mydriacyl) $0.5 \%$ unless contraindicated. A visiting diabetes educator, podiatrist, and dietician also attend most remote clinics to provide a comprehensive diabetes service. 
2.4. Image Grading and Feedback of Results. Clinical information and fundal images are transferred to an urban, regional, or locally based rural general practitioner (GP) accredited to perform DR image grading (four GPs involved). Participating GPs completed a four-hour online DR upskilling program through The University of Queensland Masters of Medicine (General Practice) program followed by an accreditation assessment through The Royal Australian and New Zealand College of Ophthalmologists (RANZCO) Queensland Faculty $[17,18]$. GPs complete a 50-patient (100 eyes) exam and must achieve at least $75 \%$ concordance with an ophthalmologist reviewer for accreditation [17, 18]. Accreditation was provided through Flinders University for one participating GP. For 2012-13 GP image grading was provided by a distant accredited GP; however, in 2014 it was performed by a locally based rural accredited GP, in collaboration with the visiting ophthalmologist.

The GP grader assesses the adequacy of the image, evaluates the image for the presence of DR or other pathology, grades DR (if present) according to the Wisconsin system, and nominates an appropriate management plan (Figure 2) [19]. An urban-based "buddy" ophthalmologist provides support to the GP grader and visits the region triannually. If no pathology is detected by the GP grader, screening results are sent to the PHC for filing, with a copy sent to the patient. If pathology is identified, results are sent to the PHC, the patient, and the patient's nominated GP to arrange ophthalmology referral. Those patients with mild or moderate nonproliferative DR (NPDR) are referred to the visiting ophthalmologist, to be seen during their triannual visit in the community closest to them (Figure 2). The "buddy" ophthalmologist is notified of any patients with severe NPDR or proliferative DR (PDR), and depending on the timing of their next visit to the region, the patient will either be reviewed by the regional ophthalmology team or urgently transferred to a larger centre with permanent ophthalmology services. Patients for whom an adequate image cannot be obtained are generally referred to the visiting ophthalmologist, as this may indicate another pathology such as cataract.

\section{Method}

3.1. Study Design. This retrospective, descriptive screening record audit had three aims:

(i) to identify the proportion of patients with documented diabetes mellitus (type 1/type 2) residing in 11 remote communities who underwent DR screening with the RODRS service,

(ii) to compare the proportion of those patients screened by the program who underwent appropriate DR screening prior to and following the implementation of the RODRS service,

(iii) to identify the proportion of screened patients with mild, moderate, or severe NPDR and PDR.

A further paper explores the acceptability of the program to patients, health professionals, and other key stakeholders.

3.2. Setting and Participants. Data was collected at PHCs during DR screening visits to 11 remote communities in a state of Australia. Eligible participants were patients with type 1 or type 2 diabetes mellitus aged 18 years or older, attending DR screening in remote communities between April 2012 and December 2014. Patients were excluded from participation if they had no perception of light in either eye, were terminally ill or deemed too unwell to participate, or had a physical or mental disability that prevented either screening or treatment. All eligible patients attending DR screening clinics were invited to take part in the study and all patients consented to participate $(n=142)$. However, one patient was screened with gestational diabetes mellitus and therefore was excluded from analysis. The Australian National Health and Medical Research Council (NHMRC) developed national guidelines for the recommended frequency of DR screening [19]. The guidelines recommend that all patients with diabetes (type 1 and type 2) undergo at least biennial screening. However, patients at high risk of DR, including Indigenous Australians and patients living in rural and remote communities, should be considered for annual examinations. In this paper "appropriate" refers to screening frequency in line with the NHMRC guidelines.

\subsection{Intervention. The RODRS service was implemented in a} Hospital District and Health Service in 2012.

3.4. Outcomes. A retrospective analysis of State Health screening data was conducted. The main outcome measures included (i) the proportion of the documented diabetic population living in remote communities who underwent DR screening with the program, (ii) the proportion of those patients screened by the program who underwent appropriate screening (in line with the NHMRC guidelines [19]) prior to and following the intervention, (iii) the quality of images captured by the screening team, (iv) the proportion of screening episodes with DR detected and the type of DR identified, and (v) the proportion of screening episodes which required ophthalmology referral. Clinical data on DR screening prior to the intervention was based on self-report. All other information was collected and accessed from State Health records.

3.5. Analysis. All screening data were entered initially into an Excel database, cleaned, and then imported into and analysed using SPSS (version 22). Histograms were viewed to assess the normality of continuous variables. Summary statistics are presented as frequency (percentage) for categorical variables and mean (standard deviation) for continuous variables that were normally distributed; otherwise median and interquartile ranges were reported. Where appropriate Chi-square tests (gender, ethnicity, and DR detection in high risk patients), Mann-Whitney $U$ (age, HbAlc), and an independent sample $t$-test (systolic and diastolic BP) were used to assess bivariate associations. A McNemar's test was performed to determine a $p$ value for proportions screened prior to and following implementation of the model. A $p$ value of $\leq 0.05$ was considered to be statistically significant.

3.6. Ethics Approval and Consent. In accordance with advice from the Human Research Ethics Committee (HREC), the 


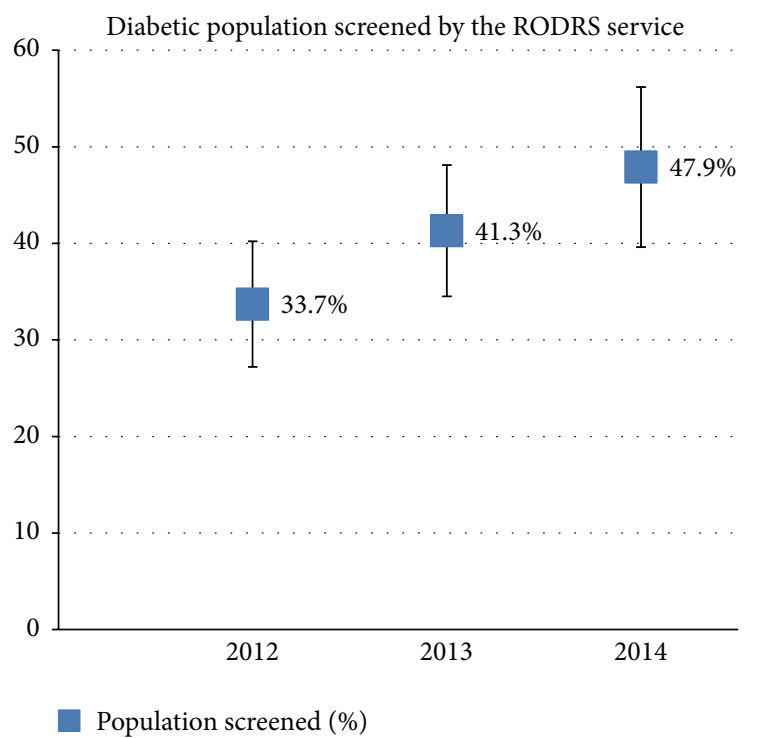

FIgURE 3: The proportion of the total documented diabetic population (residing in 11 remote communities) screened each year with $95 \%$ confidence intervals shown.

above project was compliant with the NHMRC guidance "ethical considerations in quality assurance and evaluation activities" and therefore was not recommended for HREC review (HREC/15/QRBW/122). Informed consent was obtained from all participants.

\section{Results}

4.1. Diabetic Population Screened. A total of 218 screening episodes were recorded across 11 remote communities between April 2012 and December 2014. The program screened 141 patients with 47 patients (33.3\%) screened twice and 15 patients $(10.6 \%)$ screened three times. Of the 11 remote communities visited by the screening team, eight communities were visited three times, two communities were visited twice, and one community was visited once. The proportion of the total documented diabetic population (residing in 11 remote communities) screened by the program significantly increased throughout the operation of the service from $33.7 \%$ in 2012 to $47.9 \%$ in 2014 (Table 1; Figure 3). The odds ratio for being screened in 2014 compared with 2012 was 2 (95\% CI $1.49-2.68 ; p=0.00003$ ).

4.2. Participant Demographics. A total of 141 patients were identified as eligible for participation in this study. Of these $58.2 \%$ of diabetic patients were male (Table 2). Indigenous patients comprised $23.5 \%$ of patients screened, with most Indigenous patients identifying as Australian Aboriginal. Patients ranged from 18 to 90 years of age, with a median age of 63 years. The median duration of diabetes was 6 years with $32.1 \%$ of patients considered at high risk of DR (duration of diabetes more than 10 years) $[2,20]$. This is similar to the national diabetes profile with diabetes slightly more common in males than females (5.1\% of males and $4.2 \%$ of females), although the rate of diabetes is highest amongst those aged
TABle 2: Participant demographics.

\begin{tabular}{lc}
\hline & $n=141$ \\
\hline Gender & \\
Male & 82 patients $(58.2 \%)$ \\
Female & 59 patients $(41.8 \%)$ \\
Indigenous status & \\
$\quad$ Non-Indigenous & 101 patients $(76.5 \%)$ \\
Indigenous & \\
$\quad$ Australian Aboriginal & 26 patients $(19.7 \%)$ \\
$\quad$ Aboriginal \& Torres Strait Islander & 4 patients $(3.0 \%)$ \\
$\quad$ South Sea Islander & 1 patient $(0.8 \%)$ \\
$\quad$ Total & 31 patients $(\mathbf{2 3 . 5} \%)$ \\
Age & 63 years \\
Median & 19 \\
Interquartile range & 6 years \\
Duration of diabetes & 9 \\
Median & 45 patients $(32.1 \%)$ \\
Interquartile range & \\
Duration $>10$ years &
\end{tabular}

Note: one missing record for duration of diabetes, nine missing records for Indigenous status.

TABLE 3: Clinical characteristics based on total screening episodes.

\begin{tabular}{lc}
\hline & $n=218$ \\
\hline HbAlc & $7.1 \%$ \\
Median & 2 \\
Interquartile range & 71 patients $(51.8 \%)$ \\
HbAlc $\geq 7 \%$ & 39 patients $(28.5 \%)$ \\
HbAlc $\geq 8 \%$ (high risk of DR) & \\
Hypertension & \\
Systolic BP & 140.5 mmHg $( \pm 20.3)$ \\
Mean \pm SD & 97 patients $(69.8 \%)$ \\
$\geq 130 \mathrm{mmHg}$ & 36 patients $(25.9 \%)$ \\
$\geq 150 \mathrm{mmHg}$ (high risk of DR) & \\
Diastolic BP & 82.9 mmHg $( \pm 12.0)$ \\
Mean \pm SD & 64 patients $(46.0 \%)$ \\
$\geq 85 \mathrm{mmHg}$ & 45 patients $(32.4 \%)$ \\
$\geq 90 \mathrm{mmHg}$ (high risk of DR) &
\end{tabular}

Note: four patients were missing one to two data variables.

75 to 84 years, slightly older than the population screened in this study [21].

4.3. Clinical Characteristics. The median HbAlc of diabetic patients screened by the program was 7.1\%. Overall, $51.8 \%$ of patients had an HbAlc $\geq 7 \%$ indicating poor glycaemic control and $28.5 \%$ of patients had an HbAlc $\geq 8 \%$ (associated with increased risk of DR) (Table 3) [2, 20, 22]. Systolic BP ranged from $100 \mathrm{mmHg}$ to $212 \mathrm{mmHg}$ with a mean systolic $\mathrm{BP}$ of $140.5 \mathrm{mmHg}$. Diastolic BP ranged from $54 \mathrm{mmHg}$ to $120 \mathrm{mmHg}$, with an average diastolic BP of $82.9 \mathrm{mmHg}$. Most patients had suboptimal BP control with $69.8 \%$ of patients with a systolic BP reading $\geq 130 \mathrm{mmHg}$ and $46 \%$ of patients 
DR screening prior to the implementation of the RODRS

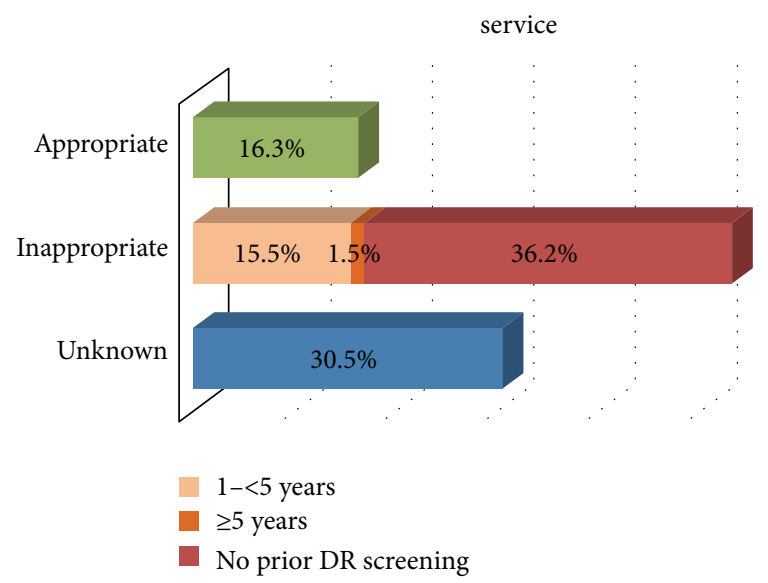

FIGURE 4: Patient reported DR screening prior to the implementation of the model $(n=141)$. Note: unknown included those patients who were not aware if they had undergone screening previously and those who had undergone screening but were unsure of the date.

with a diastolic $\mathrm{BP} \geq 85 \mathrm{mmHg}$ [22]. In addition, many patients were considered at high risk of DR with a systolic BP $\geq 150 \mathrm{mmHg}$ (25.9\%) or a diastolic BP $\geq 90 \mathrm{mmHg}(32.4 \%)$ $[2,20]$.

4.4. DR Screening Rates. Of the 141 patients screened by the program, $16.3 \%$ had received appropriate DR screening prior to the implementation of the service (screening in line with recommendations made in the NHMRC guidelines), but $36.2 \%$ of patients had never been screened (Figure 4) [19]. Following the introduction of the program, $66.3 \%$ of eligible patients received appropriate screening (odds ratio $1.93 ; 95 \%$ CI of $1.42-2.64 ; p=0.00025$ ). (Note: A total of 92 patients were included in the analysis of appropriate screening following the implementation of the model (49 patients excluded). A total of 36 patients were excluded as rescreening could not be evaluated for the following reasons: (i) screened in a community only visited once by the program (one community), (ii) screened for the first time in 2014, or (iii) screened for the first time in 2013 in those communities not visited in 2014 (two communities). A further 13 patients who were deceased or had moved from the community were excluded.) Commonly recorded reasons for not attending community screening included previous screening by an ophthalmologist or optometrist, working or travelling out of town, illness/hospitalisation, or unable to be contacted. There was no significant difference between those patients who underwent appropriate screening with the model based on gender (1.216; $1 \mathrm{df} ; p=0.27)$, Indigenous status (0.007; $1 \mathrm{df} ; p=0.93)$, age $(z=-1.84 ; p=0.07)$, HbAlc $(z=-0.37$; $p=0.71)$, systolic BP $(t=-0.29 ; p=0.77)$, or diastolic BP $(t=-0.74 ; p=0.46)$.

4.5. Image Quality. A total of $13.9 \%$ of screening episodes required rescreening due to inadequate images (Table 5). Further analysis demonstrated that the vast majority of

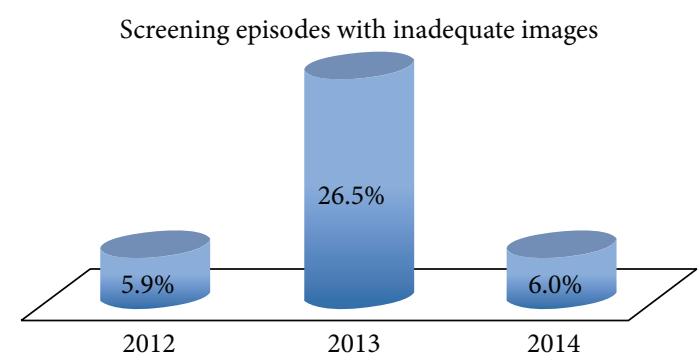

FIGURE 5: The proportion of screening episodes requiring rescreening due to inadequate images (according to GP management plan) by year.

TABLE 4: Appearance of fundi (GP grader).

\begin{tabular}{lccc}
\hline & $\begin{array}{c}\text { Left eye } \\
(n=218) \\
n(\%)\end{array}$ & $\begin{array}{c}\text { Right eye } \\
(n=218) \\
n(\%)\end{array}$ & $\begin{array}{c}\text { Screening episodes } \\
(n=218) \\
n(\%)\end{array}$ \\
\hline No DR detected & $\mathbf{1 4 2 ( 6 6 . 7 \% )}$ & $\mathbf{1 4 3 ( 6 6 . 2} \%)$ & $\mathbf{1 2 6}(\mathbf{5 8 . 9} \%)$ \\
DR detected & & & \\
Mild NPDR & $22(10.3 \%)$ & $24(11.1 \%)$ & $27(12.6 \%)$ \\
Moderate NPDR & $11(5.2 \%)$ & $14(6.5 \%)$ & $18(8.4 \%)$ \\
Severe NPDR & $2(0.9 \%)$ & $1(0.5 \%)$ & $2(0.9 \%)$ \\
Proliferative DR & $5(2.3 \%)$ & $1(0.5 \%)$ & $5(2.3 \%)$ \\
Total detected & $\mathbf{4 0 ( 1 8 . 7 \% )}$ & $\mathbf{4 0 ( 1 8 . 5 \% )}$ & $\mathbf{5 2 ( 2 4 . 3 \% )}$ \\
Inadequate image & $\mathbf{3 1 ( \mathbf { 1 4 . 6 } \% )}$ & $\mathbf{3 3 ( \mathbf { 1 5 . 3 } \% )}$ & $\mathbf{3 6}(\mathbf{1 6 . 8} \%)$ \\
\hline
\end{tabular}

Note: data was missing from two to five records.

Note: where the diagnosis differed between images of the right eye and left eye, the screening episode was categorised according to the most serious diagnosis. Where a patient had one inadequate image and the other image identified DR, the screening episode was categorised as DR.

inadequate images occurred in 2013, with a rate as high as $26.5 \%$ of screening episodes (Figure 5) and traced to a faulty camera. Following camera servicing, this decreased to $6 \%$ of screening episodes.

4.6. Diabetic Retinopathy Detection and Referral. Table 4 describes the proportion of screening episodes where images were normal, abnormal, or inadequate and required reimaging. A total of $58.9 \%$ of screening episodes were normal, $24.3 \%$ had DR detected, and $16.8 \%$ produced inadequate images. The majority of patients with DR had mild to moderate NPDR detected (21\%); however, in 3.2\% of screening episodes sight-threatening DR was detected (defined by severe NPDR or PDR). GP graders identified diabetic maculopathy in $5.6 \%$ of screening episodes, with all cases detected in 2014.

There was no statistically significant association between detection of DR and the absence or presence of appropriate DR screening prior to the implementation of the service $(0.525 ; 1 \mathrm{df} ; p=0.47)$. DR was detected more often in patients with a duration of diabetes more than 10 years and an $\mathrm{HbAlc} \geq 8 \%$, cut-offs previously shown to increase the risk of DR $[2,20]$. A total of $51.6 \%$ of patients with diabetes longer than 10 years had DR detected, compared with $25.2 \%$ of patients with no DR detected (7.798; $1 \mathrm{df} ; p=0.005)$. In 
TABLE 5: GP management plan.

\begin{tabular}{lc}
\hline & $\begin{array}{c}\text { Screening episodes } \\
(n=218) \\
n(\%)\end{array}$ \\
\hline No action & $\mathbf{1 2 5}(\mathbf{5 7 . 9} \%)$ \\
Ophthalmology referral & \\
Refer to "buddy" ophthalmologist & $55(25.5 \%)$ \\
Urgent referral & $6(2.8 \%)$ \\
Total & $\mathbf{6 1 ( 2 8 . 2 \% )}$ \\
Inadequate image & $\mathbf{3 0 ( 1 3 . 9 \% )}$ \\
\hline
\end{tabular}

Note: data was missing from two records.

Note: where the management plan differed between the right and the left eyes, the screening episode was categorised according to the most urgent management plan. Where a patient had one inadequate image and the other image identified pathology requiring ophthalmology referral, the screening episode was categorised as an ophthalmology referral.

Note: differences in the number of patients with inadequate images between Tables 4 and 5 is due to some patients being identified for ophthalmology referral due to detection of another pathology.

screening episodes where the patient's HbAlc was $\geq 8 \%$, DR was detected more often (47.1\%, compared to $23.4 \%$ with no DR) $(10.602 ; 1 \mathrm{df} ; 0.001)$. There was no statistically significant association between a diastolic $\mathrm{BP} \geq 90 \mathrm{mmHg}(0.363 ; 1 \mathrm{df}$; $p=0.547)$ or a systolic $\mathrm{BP} \geq 150 \mathrm{mmHg}$ (3.447; $1 \mathrm{df} ; p=$ 0.063 ) and detection of DR.

A total of $28.2 \%$ of screening episodes were referred to the "buddy" ophthalmologist for review of DR or secondary to identification of another pathology. This included $2.8 \%$ of screening episodes for urgent referral (Table 5).

4.7. Other Pathology. Pathology other than DR was detected in $15.1 \%$ of screening episodes. Cataract was the most commonly identified pathology and clouded fundal photographs. Macular degeneration and hypertensive retinopathy were also detected.

\section{Discussion}

The implementation of the RODRS service has significantly improved patient access to DR screening. Appropriate screening has quadrupled from $16.3 \%$ to $66.3 \%$ of patients. This is above the national population average for appropriate DR screening and is a significant achievement in remote populations with minimal to no access to optometry and ophthalmology services [6]. Since the introduction of the program, screening of the eligible diabetic population living in remote communities has become more comprehensive, increasing from $33.7 \%$ to $47.9 \%$ across its three years of operation. International rural and remote DR screening programs reported population coverage ranging from 39\% to $85 \%$ [23-31]. Indeed, achieving high rates of screening is particularly challenging in these study communities given the transient and highly mobile nature of the population, the fact that patients are often employed away from townships, the delivery of screening only once annually, and the lack of a fully coordinated approach to screening with visiting optometry and ophthalmology services. Low health literacy and limited patient contact with local health services are also recognised barriers to achieving comprehensive population coverage. It is hoped that with continued service promotion and improved community awareness, patient uptake will continue to improve.

Despite limited ophthalmology resources, a review of international rural remote DR screening models by the authors found that the majority of programs use ophthalmologists as the primary image graders. Most countries are not adequately meeting screening recommendations and the number of people with diabetes continues to rise $[6,7$, $32,33]$. Further to this, evidence suggests that on average $70 \%$ of fundal images captured show no retinopathy [17]. There is thus a need to explore innovative approaches to DR screening within a range of settings. Previous studies have demonstrated the efficacy of GP graders, with an Australian pilot of DR grading by general practitioners demonstrating good sensitivity (87\%) and specificity (95\%) [11]. During the operation of the RODRS service, just $28.2 \%$ of patients required ophthalmology referral for DR. This model may thus provide a more efficient solution to managing limited specialist ophthalmology resources in rural and remote areas.

Many international rural remote DR screening models have identified the successful integration of screen-positive patients with ophthalmology follow-up to be particularly challenging $[34,35]$. A benefit of the RODRS program is the integration of screen-positive patients with specialist follow-up through the use of a "buddy" ophthalmologist, who supports the GP grader and provides visiting services to the region. The RODRS program also integrated DR screening with other diabetes care, providing a holistic multidisciplinary diabetes service that enables patients to easily complete their annual cycle of care. The significance of this is demonstrated by data released by the National Diabetes Strategic Advisory Group indicating that just 18\% of Australian diabetics had a claim made by their GP for an annual cycle of care $[36,37]$. It is hoped that provision of a coordinated approach to diabetes care will increase the proportion of diabetic patients undergoing annual DR screening and completing their annual cycle of care.

The RODRS service is inherently unique in its delivery, using local health professionals to screen diabetic patients and a local GP to grade images. This community-based approach enables the service to tailor itself to the needs of the local population and workforce. Also notable are the high screening rates amongst the Indigenous population, comprising $23.5 \%$ of patients screened. Providing a service that meets the needs of the local Indigenous community is vitally important given that just 20\% of Indigenous Australians undergo appropriate DR screening and rates of blindness are six times higher than for non-Indigenous Australians [10].

DR was detected in $24.3 \%$ of screening episodes. This is consistent with other rural remote Australian studies with reported detection rates ranging from $11 \%$ to $45 \%$, but with the majority of programs reporting rates of 16 to $18 \%$ [23, 24, $38,39]$. This is significant and exemplifies the benefits of the program in detecting abnormality and avoiding preventable blindness. Diabetic maculopathy was identified in $5.6 \%$ of screening episodes. All cases were detected in 2014, following 
a changeover of GP graders. This could be explained by differing terminology amongst GP graders, with some graders believing they should only report diabetic macula oedema. Other Australian rural remote models have reported rates of diabetic macula oedema ranging from $0.2 \%$ to $2.8 \%$, whilst international studies reported rates of clinically significant macula oedema ranging from $4.4 \%$ to $6.1 \%[23,28,38,40-$ 42].

The recent release of the consultation paper for the development of the Australian National Diabetes Strategy has highlighted improved eye screening as a key challenge for the future [36]. Models such as this one provide a successful approach both to screening and comprehensive ongoing management of patients with DR. Further research is needed to identify the generalisability of this model in terms of infrastructure, payment models, and incentives for quality. The Australian Medical Services Advisory Committee (MSAC), the group that advises government on additional medical services nationally, has recently recommended a Medicare Benefits Schedule (MBS) item number for nonmydriatic retinal photography in primary care settings, significantly improving the feasibility of this model of care in Australian communities [43].

\section{Limitations}

Some patient records were missing clinical information. No data was available on the proportion of screen-positive patients who actually underwent follow-up by an ophthalmologist.

\section{Conclusion}

Given the increasing number of remote Australians with diabetes, the development and trial of efficient workforce solutions for DR screening are of growing importance. This innovative model has significantly improved patient access to DR screening. It utilises existing infrastructure and the local health workforce to develop a community-driven and delivered service that meets the needs of the local population. It integrates DR screening into an already existing multidisciplinary diabetes service, providing comprehensive and holistic diabetes care.
Abbreviations
DR: $\quad$ Diabetic retinopathy
RODRS: Remote outreach diabetic retinopathy screening
GP: $\quad$ General practitioner
PHC: $\quad$ Primary health care centre
IHW: Indigenous health worker
BGL: Blood glucose level
BP: $\quad$ Blood pressure
BMI: $\quad$ Body mass index
NPDR: Nonproliferative DR
PDR: $\quad$ Proliferative DR

NHMRC: National Health and Medical Research Council.

\section{Conflict of Interests}

The authors declare that they have no financial conflict of interests. However, the primary author has a personal relationship with an ophthalmologist who participated in this study.

\section{Authors' Contribution}

Lisa J. Crossland was primarily involved in the design of this study, including the design of data collection tools, with input from Nicola M. Glasson and Sarah L. Larkins. Nicola M. Glasson participated in data collection. Lisa J. Crossland and Nicola M. Glasson entered data. Data analysis was performed by Nicola M. Glasson and Sarah L. Larkins. Nicola M. Glasson drafted the paper which was critically reviewed by Lisa J. Crossland and Sarah L. Larkins. All authors approved the final paper.

\section{Acknowledgments}

This model of care was adapted from a DR screening model developed by the University of Queensland Discipline of General Practice. We would like to acknowledge the dedication of the RODRS team and thank them for their assistance in completing this paper. We would also like to acknowledge the GP graders and "buddy" ophthalmologist, many of whom worked without remuneration.

\section{References}

[1] IDF, International Diabetes Federation: IDF Diabetes Atlas, 6th edition, 2013, http://www.idf.org/diabetesatlas.

[2] Q. Mohamed, M. C. Gillies, and T. Y. Wong, "Management of diabetic retinopathy: a systematic review," Journal of the American Medical Association, vol. 298, no. 8, pp. 902-916, 2007.

[3] World Health Organization, "Priority eye diseases diabetic retinopathy," 2015, http://www.who.int/blindness/causes/priority/ en/index 5. html.

[4] L. Verma, G. Prakash, H. K. Tewari, S. K. Gupta, G. V. S. Murthy, and N. Sharma, "Screening for diabetic retinopathy by nonophthalmologists: an effective public health tool," Acta Ophthalmologica Scandinavica, vol. 81, no. 4, pp. 373-377, 2003.

[5] C. A. McCarty, C. W. Lloyd-Smith, S. E. Lee, P. M. Livingston, Y. L. Stanislavsky, and H. R. Taylor, "Use of eye care services by people with diabetes: the Melbourne Visual Impairment Project," British Journal of Ophthalmology, vol. 82, no. 4, pp. 410414, 1998.

[6] D. J. McCarty, C. L. Fu, C. A. Harper, H. R. Taylor, and C. A. McCarty, "Five-year incidence of diabetic retinopathy in the Melbourne Visual Impairment Project," Clinical and Experimental Ophthalmology, vol. 31, no. 5, pp. 397-402, 2003.

[7] S. Garg and R. M. Davis, "Diabetic retinopathy screening update," Clinical Diabetes, vol. 27, no. 4, pp. 140-145, 2009.

[8] A. C. Madden, D. Simmons, C. A. McCarty, M. A. Khan, and H. R. Taylor, "Eye health in rural Australia," Clinical and Experimental Ophthalmology, vol. 30, no. 5, pp. 316-321, 2002.

[9] C. B. Estopinal, S. Ausayakhun, S. Ausayakhun et al., "Access to ophthalmologic care in Thailand: a regional analysis," Ophthalmic Epidemiology, vol. 20, no. 5, pp. 267-273, 2013.

[10] H. R. Taylor, National Indigenous Eye Health Survey, Indigenous Eye Health Unit, Centre for Eye Research Australia and Vision CRC, 2009, http://www.vision2020australia.org.au/uploads/ resource/29/NationalIndigenousEyeHealthSurvey.pdf. 
[11] D. Askew, P. J. Schluter, G. Spurling et al., "Diabetic retinopathy screening in general practice: a pilot study," Australian Family Physician, vol. 38, no. 8, pp. 650-656, 2009.

[12] M. Bhargava, C. Y.-L. Cheung, C. Sabanayagam et al., "Accuracy of diabetic retinopathy screening by trained non-physician graders using non-mydriatic fundus camera," Singapore Medical Journal, vol. 53, no. 11, pp. 715-719, 2012.

[13] Z. Georgievski, K. Koklanis, A. Fenton, and I. Koukouras, "Victorian orthoptists' performance in the photo evaluation of diabetic retinopathy," Clinical and Experimental Ophthalmology, vol. 35, no. 8, pp. 733-738, 2007.

[14] N. Germain, B. Galusca, N. Deb-Joardar et al., "No loss of chance of diabetic retinopathy screening by endocrinologists with a digital fundus camera," Diabetes Care, vol. 34, no. 3, pp. 580-585, 2011.

[15] V. Sundling, P. Gulbrandsen, and J. Straand, "Sensitivity and specificity of Norwegian optometrists' evaluation of diabetic retinopathy in single-field retinal images-a cross-sectional experimental study," BMC Health Services Research, vol. 13, no. 1, article 17, 2013.

[16] RACQ, “Travel distance calculator," 2015, http://www.racq.com .au/travel/trip-planner.

[17] G. K. P. Spurling, D. A. Askew, N. E. Hayman, N. Hansar, A. M. Cooney, and C. L. Jackson, "Retinal photography for diabetic retinopathy screening in Indigenous primary health care: the Inala experience," Australian and New Zealand Journal of Public Health, vol. 34, supplement 1, pp. S30-S33, 2010.

[18] D. A. Askew, L. Crossland, R. S. Ware et al., "Diabetic retinopathy screening and monitoring of early stage disease in general practice: design and methods," Contemporary Clinical Trials, vol. 33, no. 5, pp. 969-975, 2012.

[19] The National Health and Medical Research Council (NHMRC), Guidelines for the Management of Diabetic Retinopathy, Australian Diabetes Society for the Department of Health and Aging, 2008, https://www.nhmrc.gov.au/_files_nhmrc/publications/attachments/di15.pdf.

[20] R. M. Schiffelers, M. H. A. M. Fens, J. M. van Blijswijk, D. I. Bink, and G. Storm, "Targeting the retinal microcirculation to treat diabetic sight problems," Expert Opinion on Therapeutic Targets, vol. 11, no. 11, pp. 1493-1502, 2007.

[21] ABS, "Australian Health Survey: Updated Results, 2011-2012. 4364.0.55.003,” 2013, http://www.abs.gov.au/ausstats/abs@.nsf/ Lookup/4364.0.55.003main+features12011-2012.

[22] Royal Australian College of General Practitioners and Diabetes Australia, "General practice management of type 2 diabetes2014-15," March 2015, http://www.racgp.org.au/your-practice/ guidelines/diabetes/.

[23] C. J. Barry, I. J. Constable, I. L. McAllister, and Y. Kanagasingam, "Diabetic screening in Western Australia: a photographer's perspective," Journal of Visual Communication in Medicine, vol. 29, no. 2, pp. 66-75, 2006.

[24] C. A. Harper, P. M. Livingston, C. Wood et al., "Screening for diabetic retinopathy using a non-mydriatic retinal camera in rural Victoria," Australian and New Zealand Journal of Ophthalmology, vol. 26, no. 2, pp. 117-121, 1998.

[25] S. J. Lee, C. A. McCarty, C. Sicari et al., "Recruitment methods for community-based screening for diabetic retinopathy," Ophthalmic Epidemiology, vol. 7, no. 3, pp. 209-218, 2000.

[26] A. McKenzie and J. Grylls, "Diabetic retinal photographic screening: a model for introducing audit and improving general practitioner care of diabetic patients in a rural setting," Australian Journal of Rural Health, vol. 7, no. 4, pp. 237-239, 1999.
[27] E. Reda, P. Dunn, C. Straker et al., "Screening for diabetic retinopathy using the mobile retinal camera: the Waikato experience," New Zealand Medical Journal, vol. 116, no. 1180, p. U562, 2003.

[28] P. Romero, R. Sagarra, J. Ferrer, J. Fernández-Ballart, and M. Baget, "The incorporation of family physicians in the assessment of diabetic retinopathy by non-mydriatic fundus camera," Diabetes Research and Clinical Practice, vol. 88, no. 2, pp. 184$188,2010$.

[29] N. Hautala, R. Aikkila, J. Korpelainen et al., "Marked reductions in visual impairment due to diabetic retinopathy achieved by efficient screening and timely treatment," Acta Ophthalmologica, vol. 92, no. 6, pp. 582-587, 2014.

[30] R. Lemmetty and K. Mäkelä, "Mobile digital fundus screening of type 2 diabetes patients in the Finnish county of SouthOstrobothnia," Journal of Telemedicine and Telecare, vol. 15, no. 2, pp. 68-72, 2009.

[31] T. Peto and C. Tadros, "Screening for diabetic retinopathy and diabetic macular edema in the United Kingdom," Current Diabetes Reports, vol. 12, no. 4, pp. 338-345, 2012.

[32] R. McKay, C. A. McCarty, and H. R. Taylor, "Diabetic retinopathy in Victoria, Australia: the visual impairment project," British Journal of Ophthalmology, vol. 84, no. 8, pp. 865-870, 2000.

[33] P. P. Goh, M. A. Omar, and A. F. Yusoff, "Diabetic eye screening in Malaysia: findings from the National Health and Morbidity Survey 2006," Singapore Medical Journal, vol. 51, no. 8, pp. 631634, 2010.

[34] S. J. Lee, P. M. Livingston, C. A. Harper, C. A. McCarty, H. R. Taylor, and J. E. Keeffe, "Compliance with recommendations from a screening programme for diabetic retinopathy," Australian and New Zealand Journal of Ophthalmology, vol. 27, no. 3-4, pp. 187-189, 1999.

[35] D. B. Mak, A. J. Plant, and I. McAllister, "Screening for diabetic retinopathy in remote Australia: a program description and evaluation of a devolved model," Australian Journal of Rural Health, vol. 11, no. 5, pp. 224-230, 2003.

[36] The National Diabetes Strategy Advisory Group, "A strategic framework for action: consultation paper for the development of the Australian National Diabetes Strategy," 2015, http://www .diabetesaustralia.com.au/Documents/DA/Media\%20Releases/ National\%20Diabetes\%20Strategy\%20Consultation\%20Paper .pdf.

[37] Australian Institute of Health and Welfare (AIHW), "Annual Cycle of Care," May 2015, http://www.aihw.gov.au/diabetesindicators/annual-cycle-of-care/.

[38] R. B. Murray, S. M. Metcalf, P. M. Lewis, J. K. Mein, and I. L. McAllister, "Sustaining remote-area programs: retinal camera use by Aboriginal health workers and nurses in a Kimberley partnership," Medical Journal of Australia, vol. 182, no. 10, pp. 520-523, 2005.

[39] S. J. Lee, C. Sicari, C. A. Harper et al., "Examination compliance and screening for diabetic retinopathy: a 2-year follow-up study," Clinical and Experimental Ophthalmology, vol. 28, no. 3, pp. 149-152, 2000.

[40] R. Ling, V. Ramsewak, D. Taylor, and J. Jacob, "Longitudinal study of a cohort of people with diabetes screened by the Exeter Diabetic Retinopathy Screening Programme," Eye, vol. 16, no. 2, pp. 140-145, 2002.

[41] S. McHugh, C. Buckley, K. Murphy et al., "Quality-assured screening for diabetic retinopathy delivered in primary care in Ireland: an observational study," British Journal of General Practice, vol. 63, no. 607, pp. e134-e140, 2013. 
[42] P. Massin, A. Chabouis, A. Erginay et al., "OPHDIAT: a telemedical network screening system for diabetic retinopathy in the Île-de-France," Diabetes and Metabolism, vol. 34, no. 3, pp. 227-234, 2008.

[43] Medical Services Advisory Committee, "Public summary document: application 1181-non-mydriatic retinal photography in people with diagnosed diabetes," 2014, http://www.msac.gov .au/internet/msac/publishing.nsf/Content/1181-public. 


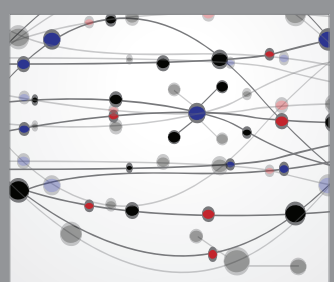

The Scientific World Journal
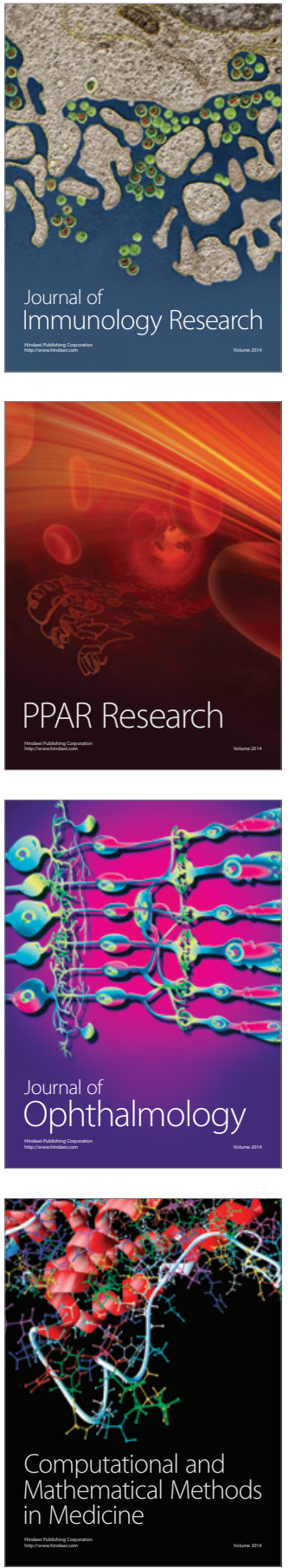

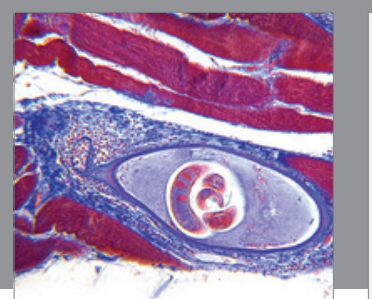

Gastroenterology Research and Practice

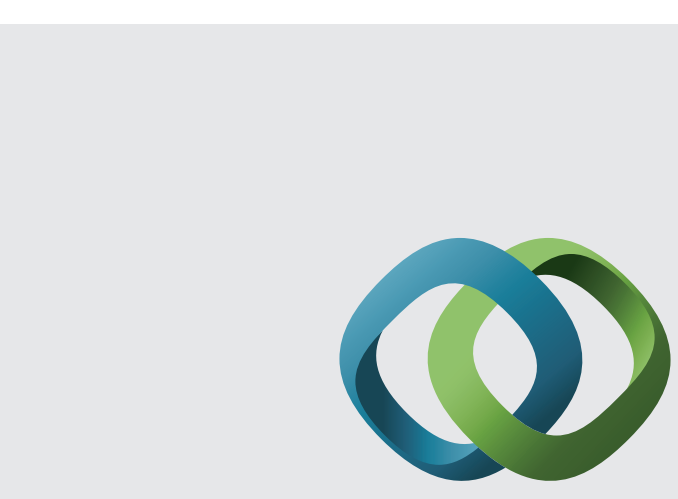

\section{Hindawi}

Submit your manuscripts at

http://www.hindawi.com
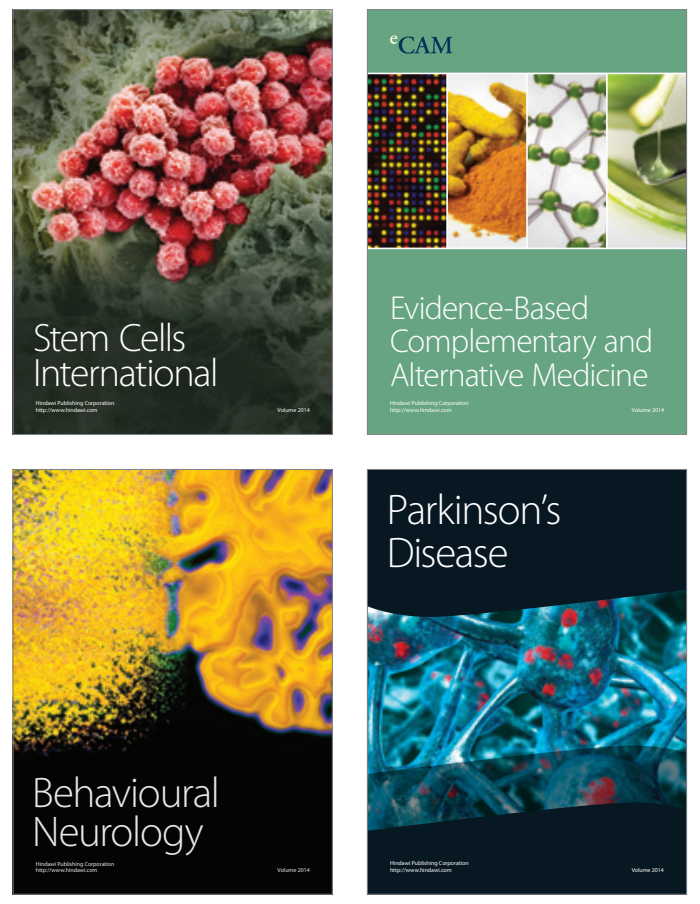
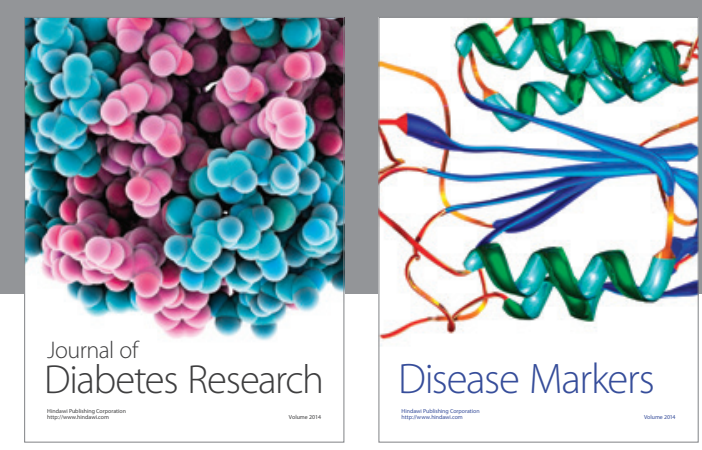

Disease Markers
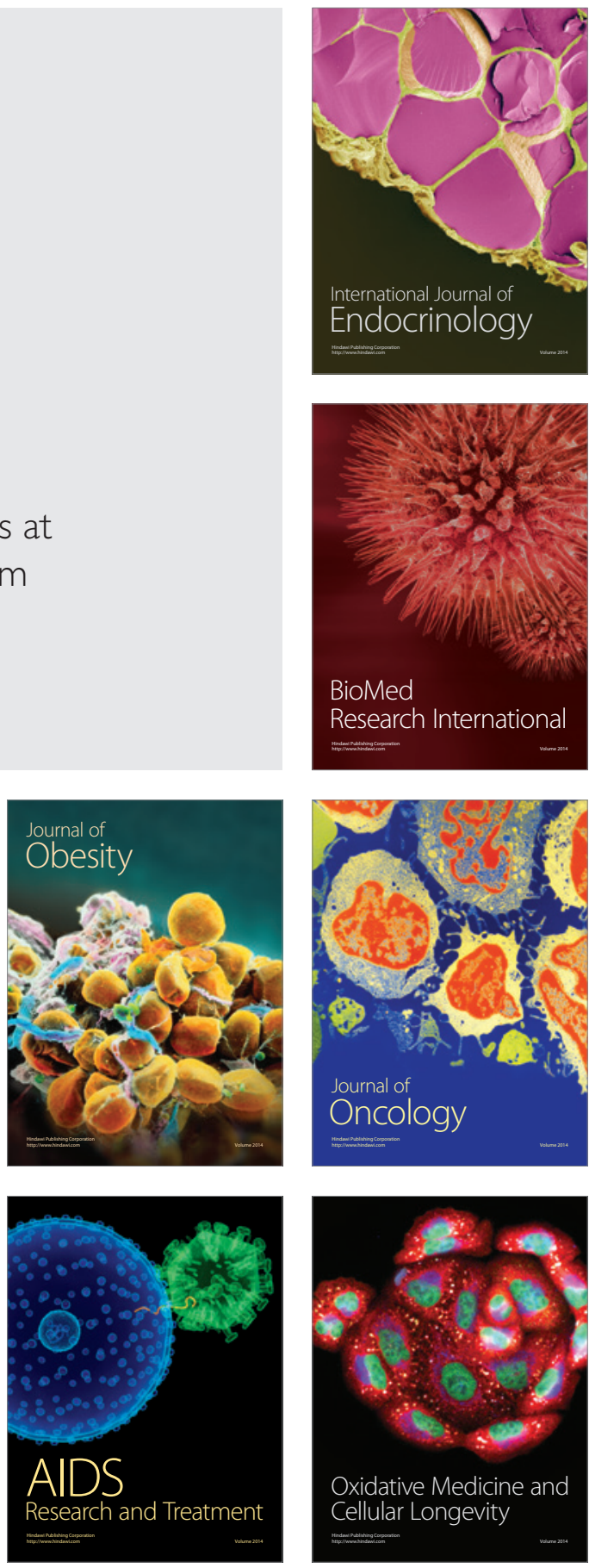